\title{
LabSocket: A New Trend in Remote Labs
}

\author{
http://dx.doi.org/10.3991/ijoe.v9iS5.2787 \\ D.Ursutiu ${ }^{1}$, C.Samoila ${ }^{1}$ and J.Bergmans ${ }^{2}$ \\ ${ }^{1}$ University "Transylvania", Brasov, Romania \\ ${ }^{2}$ Bergmans Mechatronics LLC, Newport Beach, USA
}

\begin{abstract}
Many companies and universities understand the trends of evolution in direction of "Remote Engineering RE" like a strong need to sustain the development and especially the fast and deep evolution in the field of "Virtual Instrumentation - VI" with direct connection in engineering and education. In this paper we combine a new system "LabSocket - LS" with a recognized standard in education "National Instruments Engineering Laboratory Virtual Instrumentation - Suite NI ELVIS" and the new myDAQ board for students hands-on laboratories. In recent years at the Creativity Laboratory from "Transylvania" University of Brasov - Romania many LabVIEW applications based on NI ELVIS and myDAQ have been developed. Now, based on the LabSocket system developed by Bergmans Mechatronics LLC, we can begin to control these applications over the web, and thereby increase the learning opportunities offered to the students. A significant attribute of the LabSocket system is that it extends the functionality of LabVIEW-based industrial or educational applications to the browser, without the use of browser plug-ins or requiring developers to write any HTML or JavaScript code.
\end{abstract}

Index Terms-Education, LabSocket, LabVIEW, Remote Engineering, Virtual Instrumentation,.

\section{INTRODUCTION}

The LabVIEW application developed by National Instruments enables scientists and engineers to rapidly develop data acquisition and control systems through a combination of an easy-to-understand graphical programming language and an intuitive user interface design framework. LabVIEW software is well-suited to be operated locally by a user. Remote access to a LabVIEW application, however, has to date been limited by either complex solutions (e.g. interaction with LabVIEW's Web Services interface [1]), platform requirements (e.g. requiring the use of browser plug-ins that only operate on certain platforms [2][3] , platform-specific solutions [4]); or, the need to manually create client-side software [4].

The LabSocket system, developed by Bergmans Mechatronics, is an alternate solution that easily enables remote access to a LabVIEW application using almost any modern desktop or mobile browser. In this paper, we describe the LabSocket system and show how the system can enable educators to provide students with remote access to National Instruments NI ELVIS (or myDAQ) and different data acquisition hardware platforms.

\section{LABSOCKET TECHNOLOGY}

\section{A. Figures and Tables}

The LabSocket system consists of several components. The first of these is a pair of support VIs that is placed in the block diagram of VI that the developer wishes to make available on the Web. In LabSocket terminology, this VI is defined as the "Target VI". Two other key components are a web server and message broker. These latter components can be located on the same platform as the LabVIEW application, a server on a local area network or on a "cloud" server.

On starting the Target VI, LabSocket support VIs examines the Target VI front panel and create JavaScript and HTML code that will render each front panel element in a web browser. This code is then transferred to a directory served by the web server.

Synchronization of the Target VI and browser is then maintained as follows. When a user points a browser to the web page replica of the Target VI, a connection is automatically established between the browser and Target VI via the message broker. The LabSocket system then monitors the Target VI front panel for user or programmatically initiated changes. Any change is transmitted to the browser which then updates the rendered page in the browser. Similarly, the system also monitors for user initiated changes in the browser and transmits any changes back to the LabVIEW front panel.

LabSocket employs the HTML5 WebSocket standard [5] for continuous, bi-directional communication between the message broker and browser. This standard is the basis for the name of the system: "LabSocket" = LabVIEW + WebSocket.format.

\section{CREATIVITY LABORATORY}

In the year 1998 in one TEMPUS project was created, like one autonomous department in University "Transylvania" of Brasov, the Center for Valorization and Transfer of Competences CVTC. This center act in the last years like one active and well recognized poll for research and international cooperation in different projects and in the same time one powerful center involved in student education and industrial training and competence transfer.

The Center for Valorization and Transfer of Competences CVTC together with important European partners started one International Association of Online Engineering IAOE (http://www.online-engineering.org). This association is an international non-profit organization with the objective of encouraging the wider development, distribution and application of Online Engineering (OE) technologies and its influence to the society. In the same time IAOE organize important conferences and publish more referenced journals. One of them is Remote Engineering and Virtual Instrumentation Conference (REV).

From 2005 inside CVTC was organized in collaboration and supported by National Instruments one Creativity Laboratory. Inside this laboratory was installed $16 \mathrm{NI}$ 


\section{SPECIAL FOCUS PAPER \\ LABSOCKET: A NEW TREND IN REMOTE LABS}

ELVIS systems, many DAQ boards and systems and year by years we increased all the facilities offered to our students and for industrials training by different other software's (LabVIEW, Multisim, Ultiboard, VEE-Pro, ImagePro-Plus, etc.), different measuring systems (from Agilent Technologies, EcoChemie, Fluke, LabJack, Meilhaus Electronic, Keithley, Stanford Research etc.).

The teams from Creativity Laboratory were focused on creating a base of top materials, enabling advanced research and advanced training. Second, efforts have been made to bring on the Romanian market prestigious companies that would be co-interested in training highly qualified human resources.

Based on NI ELVIS systems were creating a strong platform for creative education and training using:

- Multisim for simulation and Multiboard for PCB design;

- With the classic NI ELVIS board for circuit prototyping - students can now compare simulation results with the real NI ELVIS measurements;

- The National Instruments Digital Electronics FPGA board (NI DE FPGA) to offer a complex platform for creative electronic design (software reconfigurable applications);

- DATEX Emona boards to add the necessary support for "communication labs";

- FOTEX Emona boards to make a better training in fiber optic transmission and communication field;

- The Freescale Semiconductors MKU SLK boards for NI ELVIS microcontroller applications etc.

All these facilities and developments - offer a modern and complex system - used to develop many laboratory works. Now - like a normal step - we need to add the possibility to "remote control" all this facilities and laboratory works.

We can use from start the LabVIEW publishing tool facilities. LabVIEW remote front panels [2] allow multiple clients to simultaneously view the front panel of the same LabVIEW created Virtual Instrument VI, however, by default, only one client can control the VI at one time. In the new LabVIEW versions, multiple clients can control the VI's front panel at the same time. A new instance of the front panel is created each time control is granted which allows each client to control the VI without affecting any of the other clients. The only problem with this technology - at the level of the client PC or Laptop - is the need to install the corresponding LabVIEW "Run Time Engine" (RTE) and in many cases people do not like to or cannot do this kind of installation.

For this reasons we started to develop our remote control application based on the LabSocket technology which offers similar facilities and no needs to install additional software on the client platform.

\section{LABSOCKet LABS PROTOTYPING}

First tests to using the NI ELVIS and/or myDAQ devices from Creativity Laboratory was done directly using the Bergmans Mechatronics LLC servers from USA and can be done by anybody using the demo downloadable from http://labsocket.com/download.html. We present the block diagram of this system with NI ELVIS (myDAQ) and all the software and hardware components in Fig.1.

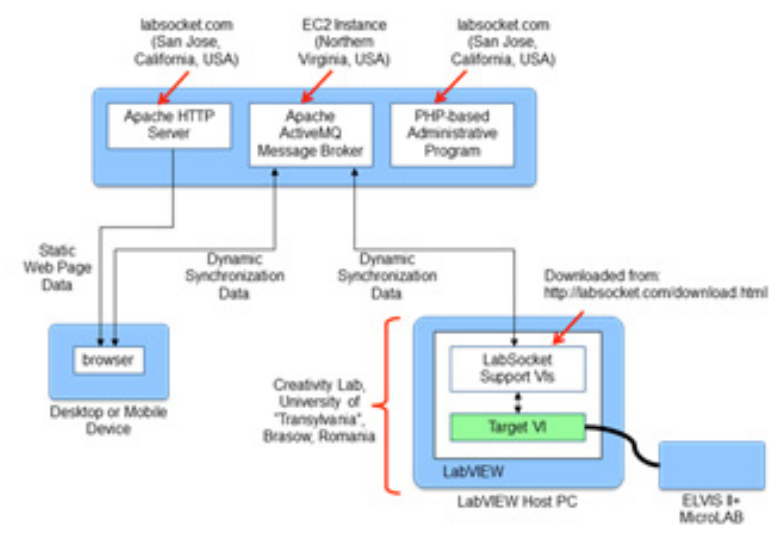

Figure 1. Testing the LabSocket technology with NI ELVIS (or myDAQ)

First applications and test was done with NI ELVIS II+ system and the LabSocket demo package presented in Fig.1. We do a simple experiment with one "DC motor" connected with a flexible connection to one "tachometer" (Fig.2.). Was used a solar kit DC Motor with operating voltage from 1.2 and operating current $55 \mathrm{~mA}$ (controlled with one of the Variable Power Supplies VPS from NI ELVIS) and one Beckman DC Tachometer 6.5V at 1000 R.P.M. (measured with Analog Input Channel AI0 from NI ELVIS system).

\section{A. NI ELVIS Laboratory work:}

The final measurement system is presented in Fig.2. The student can regulate the motor speed and measure the rotation with the DMM and visualise the signal (and measure it) with the NI ELVIS Scope connected at the AI0.

In the same Fig. 2 we can see the PC desktop:

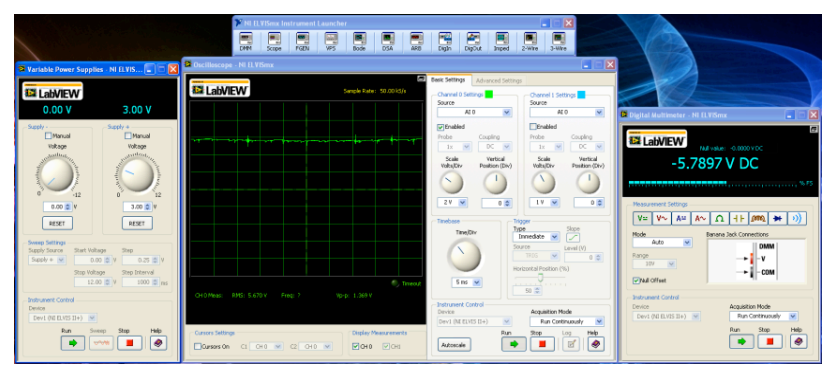

a) NI ELVIS LabVIEW Control

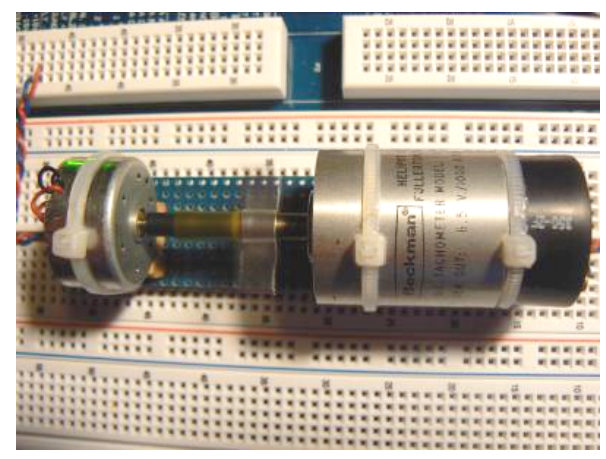

b) DC Motor and Tachometer

Figure 2. NI ELVIS laboratory measurements

- NI ELVISmx Instrument Launcher is at the top of the picture 


\section{SPECIAL FOCUS PAPER \\ LABSOCKET: A NEW TREND IN REMOTE LABS}

- From the Instrument launcher the student must start the Variable Power Supplies VPS (on the left side of the picture)

- Also, the student can launch the NI ELVIS Scope (in centre of the picture) and/or the Digital Multimeter (right side of picture)

\section{B. Remote Control with the LabSocket:}

We performed a simple experiment to demonstrate that the same laboratory experiment can easily be remotely controlled from any web browser using the LabSocket system. We developed one LabVIEW control application and through LabSocket, this application can be controlled from modern web browser on a wide of platforms, including PC, iPhone and iPad. In Fig. 3 we present the running LabVIEW VI (LabSocket Demo - Simple.vi) operating on a PC running Windows 7 Professional and the representation of the VI in an IE10 browser and the Safari browser on iPhone.

We presented one conventional method of measuring RPM using a device called a tachometer, which can precisely measure the speed of up to thousands of RPM. There are namely two types of tachometers, the "contact" and "non-contact" tachometers.

The contact tachometer is physically attached to the motor shaft (as in our case), thereby reducing the speed, and providing not so accurate RPM reading.

The non-contact tachometer utilizes a brightness sensor that detects rotations. For instance, when a motor spins with a black-white colored disc attached to the shaft, the tachometer flashes the rotating disc with an LED and can

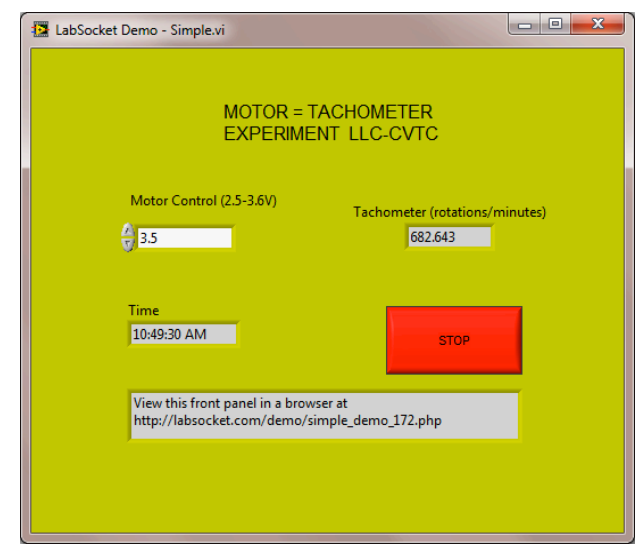

a) LabVIEW Front Panel

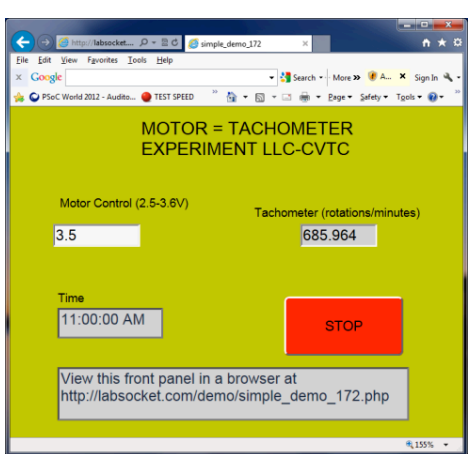

b) LabSocket Representation in IE 10 Browser on Windows 7

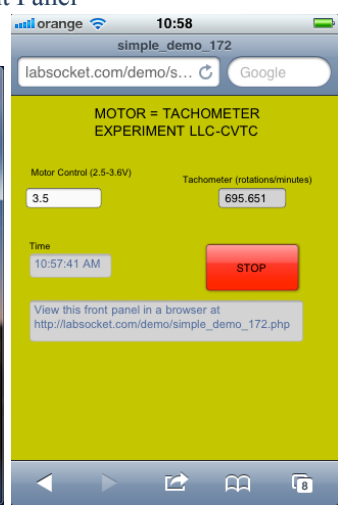

c) LabSocket Representation in Safari Browser on iPhone
Figure 3. DC Motor connected with the Tachometer "see" the varying light reflection from light to dark, through its brightness sensor. A chip measures the time for a light to dark to light progression, and from this information, the RPM can be calculated

Students can modify the laboratory and make a new development to build a non-contact tachometer.

It is important to be able to interpret the speed of a DC motor using RPM units, because as you learn more about electronic technology you will likely come across a different unit of speed for the DC motor. The internationally accepted metric unit for angular velocity is radian per second ( $\mathrm{rad} / \mathrm{s})$. RPM and $\mathrm{rad} / \mathrm{s}$ are both used to measure the same thing.

To convert angular velocity in units of RPM (revolutions per minute) to radians per second ( $\mathrm{rad} / \mathrm{s})$, we must multiply the velocity in RPM by $0.10472(=\pi / 30)$. To convert $\mathrm{rad} / \mathrm{s}$ back to units of RPM, multiply velocity in $\mathrm{rad} / \mathrm{s}$ by $9.54929(=30 / \pi)$.

Students can develop the LabVIEW virtual instrument directly to make this conversion when they measure the motor speed! After they complete one web controlled application using the LabSocket system, they can exchange it with other students via the INTERNET!

\section{Laboratory and Remote Experiment with MicroLAB:}

Looking at the Creativity Laboratory for a versatile easy to handle and portable hands-on device like the NI ELVIS laboratory system, we put together the myDAQ NI [6] card and the low cost AX-1 digital experimental board from Innovative Experiment (INEX) Company [7] and we developed one low price MicroLAB (see the Fig. 4 a-b).

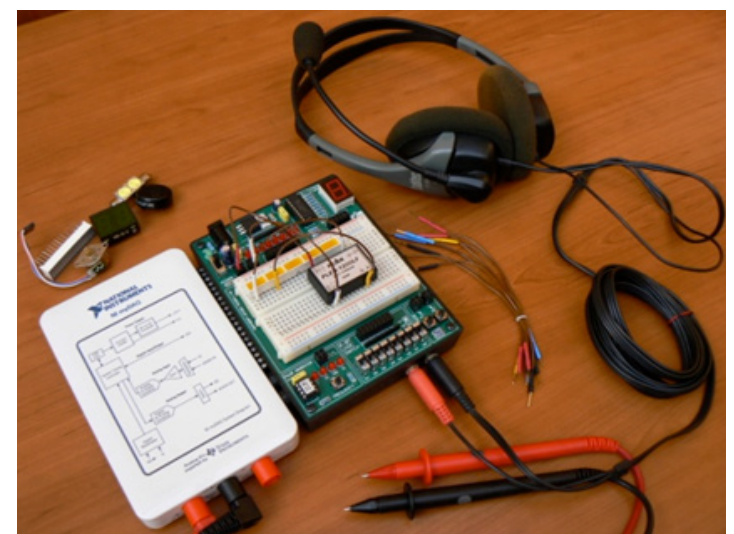

a)

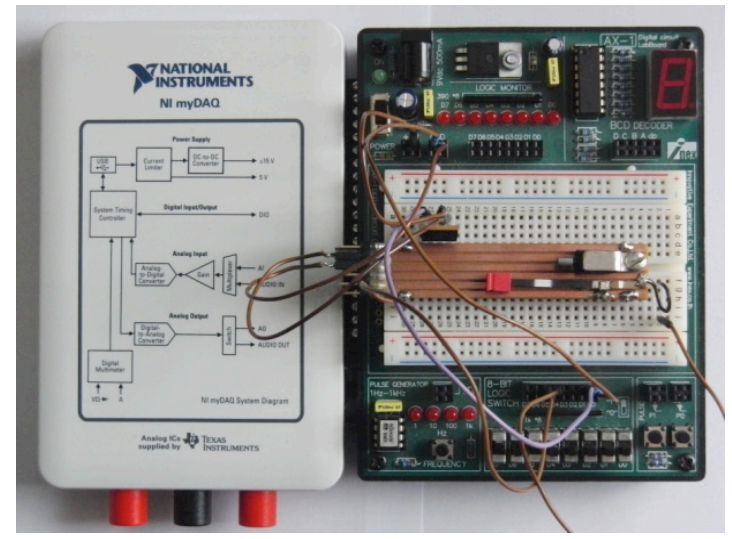

b)

Figure 4. (a) The new MicroLAB device and (b) Vibration Lab 


\section{SPECIAL FOCUS PAPER \\ LABSOCKET: A NEW TREND IN REMOTE LABS}

In Fig.4 (b) we present one simple application built on MicroLAB for investigation of the mechanical resonance. We used a mobile phone "vibrator" powered by a MOSFET from the AX1 card (all the system USB self powered) and one "bimorphous" piezo system to measure the vibration. Using a small mass (the red mass one in Fig.4b) on the bimorphous piezo resonator we selected the resonance in the range of speed offered by the vibrator.

Our students can do now simple experiments (in our labs or in their homes), and then compare the result with the remote controlled lab (see screenshots of the lab user interfaces in Fig.5) or can exchange their experiments with other students working in the INTERNET.

By this system we attract students to be more involved and spend more time in doing engineering and physics experiments. The energy recuperated from the bimorphous system can be used in other laboratory works connected with "energy harvesting" systems.

\section{FUTURE LABSOCKET DEVELOPMENT}

While the current version of the LabSocket system has demonstrated the capability to remotely monitor and control LabVIEW applications over the web, further development efforts are underway to improve the system for educational and industrial users.

For example, in response to user requests for improved data plotting capability, support for LabVIEW Waveform Graphs, Waveform Charts and XY Graphs is being developed. Figure 6 shows the prototype Waveform Chart capability in action. Full support for these front panel data plotting elements is planned for June 2013. Figure 6 also illustrates the implementation of support for LabVIEW slider bars.

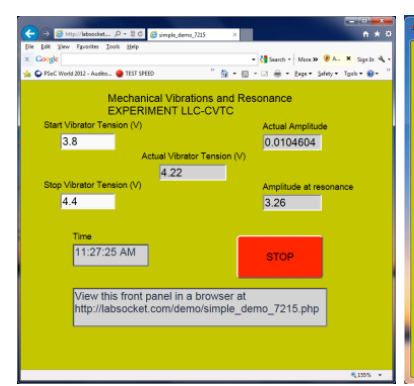

a) LabVIEW Front Panel

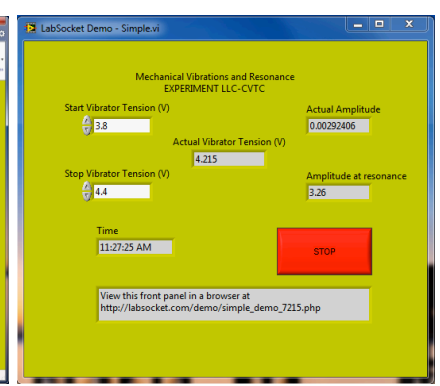

b) IE10 Browser Control

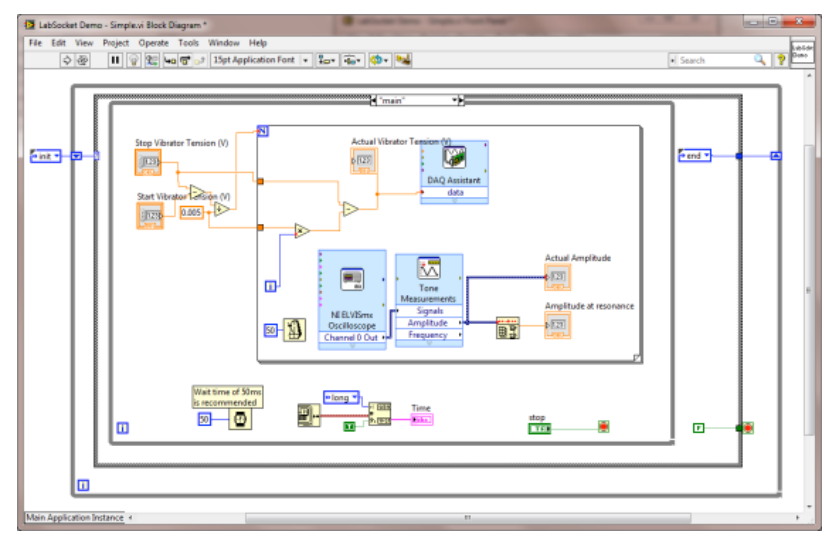

b) LabVIEW Diagram

Figure 5. Mechanical Resonance Experiment using MicroLAB Panel, web control and Diagram)
In addition, we have shown that it is possible to integrate the LabSocket system with the Moodle Course Management System [8] (Figure 7). One area of planned work to improve integration with Moodle is the management and control of user access to laboratory experiments.

\section{PHILOSOPHY OF OUR EFFORTS}

In the new paradigm of the knowledge-based economy, all of the assessments and evaluations indicated the fact that intangible knowledge became the most important asset in the case of all companies. In the traditional model of teaching, universities were considered isolated and acting under own regulations (conservative model). The connection between knowledge creation and society was at teacher decision. This model is changed in evolutionary economy model, and universities become the central point

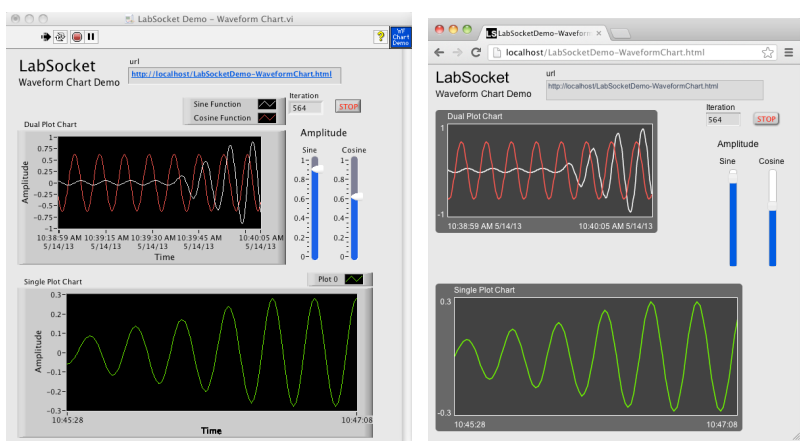

Figure 6. Prototype Waveform Chart Capability Implemented in LabSocket System (Left - LabVIEW Front Panel, Right - Representation in Chrome Browser on Mac)

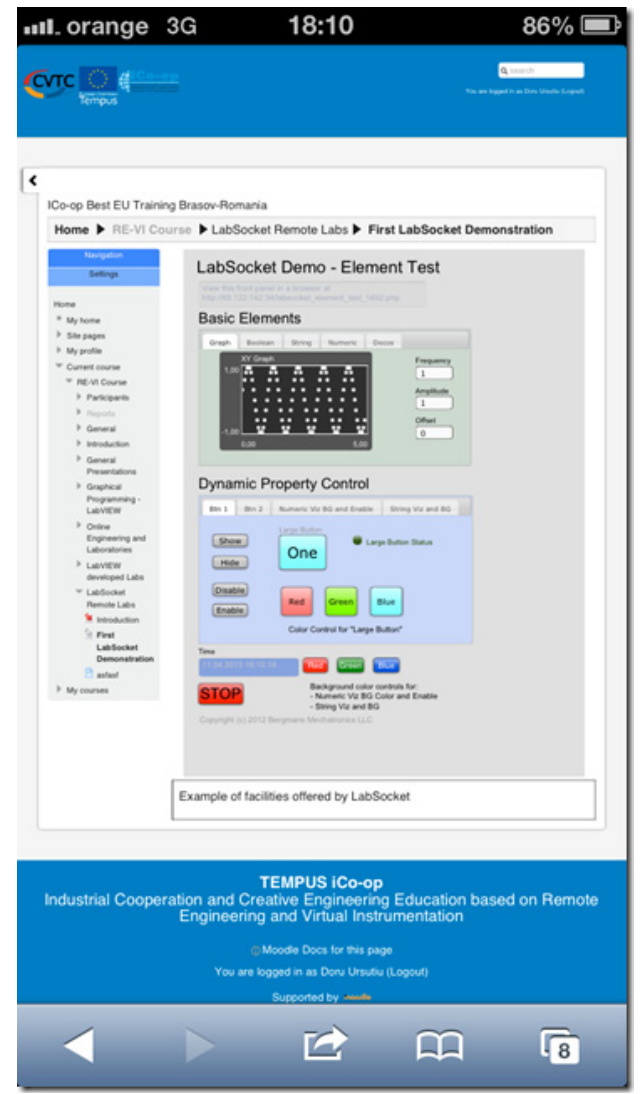

Figure 7. Initial Integration of LabSocket with Moodle Course Management System 


\section{SPECIAL FOCUS PAPER \\ LABSOCKET: A NEW TREND IN REMOTE LABS}

of knowledge creation as a future asset for main beneficiary - companies. In existed theories, knowledge creation has two explanations: one is that knowledge creation is a result of the interplay between intangible and tangible knowledge (Nonaka-1994, Konno-2000) and other is that knowledge creator is experiential learning model (Kolb-1984).

As in many cases the best way is to unify these models, so that to force the modification of the natural behavior of human beings. This force was demonstrated by practice that is the unification between learning, (where act the contradiction between teachers' tendency to maximize the knowledge quantity transferred and "minimum resistance" manifested by the learners), knowledge creation as a result of increasing tangible knowledge and implicitly increasing of intangible ones as a engine of knowledge creation, and application skills (problem solving). The above described efforts of CVTC Creativity Laboratory were designed in this direction

\section{CONCLUSIONS}

Our work with the combination of NI ELVIS - MicroLAB - LabSocket in the Creativity Laboratory proved how flexible and useful can be this platform for engineering education.

Many of our students start to acquire myDAQ devices and to use it in their homes and at the same time to develop their self modules for myDAQ (like INEX AX1).

Combining local laboratories (based on NI ELVIS) with hands-on labs (based on myDAQ, MicroLAB) and LabSocket technologies for simple or complex LabVIEW remote labs will be well suited for modern Engineering Education.

\section{REFERENCES}

[1] "Web Services in LabVIEW", http://www.ni.com/whitepaper/7350/en, Accessed Dec 15, 2012.

[2] "Remote Panels in LabVIEW -- Distributed Application Development", http://www.ni.com/white-paper/4791/en, Accessed Dec $15,2012$.

[3] "NI LabVIEW Web UI Builder Product Information", http://www.ni.com/uibuilder/, "NI LabVIEW Web UI Builder Product Information”, Accessed Dec 15, 2012.

[4] "Data Dashboard for LabVIEW", https://decibel.ni.com/ content/docs/DOC-19387, Accessed Dec 15, 2012

[5] "WebSocket", http://en.wikipedia.org/wiki/WebSocket. Accessed May 17, 2013

[6] "NI myDAQ Circuits Curriculum Resources", http://www.ni.com/white-paper/11464/en, Accessed Dec 15, 2012.

[7] "AX-1documentationandspecifications", http://www.inexglobal. com/products.php?type =EXPERIMENT\&cat=EXPERIMENT\&m odel=ax 1 , Accessed Dec 15, 2012.

[8] "Moodle Course Management System", https://moodle.org/, Accessed May 14, 2013.

\section{AUTHORS}

D. Ursutiu is with the Creativity Laboratory CVTC of University "Transilvania" of Brasov, RO-500036 Str. Eroilor 29, Brasov, Romania (e-mail udoru@unitbv.ro)

C. Samoila is with the Creativity Laboratory CVTC of University "Transilvania" of Brasov, RO-500036 Str. Eroilor 29, Brasov, Romania (e-mail csam@unitbv.ro)

J. Bergmans is with Bergmans Mechatronics LLC, Newport Beach, California USA (e-mail: jbergmans@bergmans.com).

This article is an extended and modified version of a paper presented at the EDUCON2013 conference held at Technische Universität Berlin, Berlin, Germany from March 13-15, 2013. Received 17 May 2013. Published as resubmitted by the authors 27 May 2013. 